\title{
Estilos Políticos y Orientación Tecnocrática bajo los Gobiernos de Lagos y Bachelet
}

\author{
PATRICIO SILVA \\ Universidad de Leiden
}

\section{Resumen}

Este artículo explora de qué manera Ricardo Lagos y Michelle Bachelet han abordado el tema de la tecnocracia durante sus respectivos gobiernos. Para ello se presta especial atención a los estilos políticos utilizados por ambos presidentes y como éstos facilitan o obstaculizan el accionar tecnócratico al interior de sus administraciones. Se argumenta que la posición que ambos líderes adoptan ante los estamentos tecnocráticos al interior de sus gobiernos se encuentra fuertemente condicionada por el tipo de relación que estos presidentes establecen con las dirigencias de los partidos políticos que participan en la coalición gubernamental. Además, se subraya la existencia de una lucha sórdida entre políticos tradicionales y tecnócratas por el poder político y la influencia sobre la figura del presidente al interior de ambas administraciones. El Presidente Lagos siempre desconfió de la tecnocracia y sólo hizo uso estratégico de ésta para atender a problemas de legitimidad ante las clases empresariales y la comunidad financiera internacional respecto a la conducción económica del país. Por su parte, Michelle Bachelet se verá obligada a aceptar el apoyo de la tecnocracia de 'Expansiva' en vista de la siempre problemática relación entre ella y las cúpulas políticas concertacionistas.

Palabras claves: Estilos Políticos - Tecnocracia - Relación Presidente-Partidos Políticos.

\section{Abstract}

This article explores the ways in which Presidents Lagos and Bachelet have dealt with the technocratic phenomenon within their respective governments. For this purpose, special attention is given to the political styles characterizing both presidents and the manner in which these styles have facilitated or obstructed the functioning of technocratic groups within governmental circles. As it is argued, the attitude adopted by both leaders vis-à-vis the presence of technocratic groups within their governments is largely conditioned by the type of relation established between the presidents and the supporting political parties. In addition to this, a sordid clash between politicians and technocrats for power and influence can be observed. President Lagos always distrusted the technocracy. He only made strategic use of it in order to legitimate his conduction of the country's economy towards entrepreneurial groups and the international financial community. On the other hand, President Bachelet will be forced to seek support from the 'Expansiva' technocrats due to her problematic relation vis-à-vis the leaders of the Concertación's political parties.

Key Words: Political Styles - Technocracy - Relationship President-Political Parties. 
Revista de Sociolocía 21 / 2007 Chile Hoy

Facultad de Ciencias Sociales - Universidad de Chile

\section{Introducción}

Desde el inicio de la era de los gobiernos concertacionistas en 1990 Chile ha experimentado profundas transformaciones en el terreno socio-económico, político, institucional y cultural. Sin embargo, podemos constatar la persistencia de estilos políticos de carácter tecnocrático que muestran cierta similitud al utilizado anteriormente por la tecnocracia neoliberal al servicio del gobierno del General Pinochet.Y efectivamente los gobiernos de Patricio Aylwin (1990-1994), Eduardo Frei (1994-2000), Ricardo Lagos (2000-2006) y de Michelle Bachelet (2006-) también han privilegiado la constitución de poderosos equipos tecnocráticos que han quedado a cargo de la conducción económica del país. Estos gobiernos también han adoptado, si bien en diferentes grados, un discurso tecnocrático basado en la modernización de la economía y del sector público, en la búsqueda de la eficiencia y en la constitución de un 'gobierno de los mejores'.

Este artículo tiene como objeto analizar la manera en que los dos gobernantes socialistas de la Concertación, Ricardo Lagos y Michelle Bachelet, han articulado sus equipos políticos y económicos, enumerando una serie de factores que han influido en la balanza del poder entre políticos y tecnócratas durante sus gobiernos. Para esto se prestará especial atención a los estilos políticos que caracteriza a ambos gobernantes que, a mi juicio, constituyen un factor importante para explicar el por qué de sus decisiones de debilitar o fortalecer la presencia y el poder relativo de los grupos tecnocráticos al interior de sus respectivos gobiernos.

La posición de los tecnócratas en ambos gobiernos también se verá condicionada por la manera en que Lagos y Bachelet se ha relacionado con los partidos políticos que conforman la Concertación. Ademas, la existencia de conflictos abiertos o encubiertos entre líderes políticos y tecnócratas en torno a sus cuotas de poder e influencia en el proceso de toma de decisiones, constituirá un fenómeno recurrente en ambas administraciones.

\section{Lagos y sus Asesores del "Segundo Piso"}

Las elecciones presidenciales de 1999-2000 fueron una de las más reñidas desde que se restauró el orden democrático en 1990. Ricardo Lagos y Joaquín Lavín debieron luchar literalmente por cada voto ya que ambos candidatos tenían las mismas probabilidades de resultar ganador en esta contienda electoral. También por primera vez desde 1990 se requirió de una segunda vuelta electoral para decidir quien sería el futuro presidente de Chile. ${ }^{1}$ Mientras que en la primera vuelta Lagos y Lavín terminaron prácticamente igualados, en la vuelta definitiva Lagos solo logró superar con una diferencia mínima a su rival de derecha. ${ }^{2}$

Estas elecciones tuvieron lugar el 12 de diciembre de 1999 y el 16 de enero de 2000, respectivamente.

En la primera vuelta Lagos obtuvo el 47,95 por ciento de los votos (contra el 47,51 por ciento que

logró Lavin). En la vuelta final Lagos logró el 51,31por ciento de los votos (y Lavín el 48,69 por ciento). 
Por mucho tiempo se pensó que las elecciones de diciembre de 1999 darían una victoria holgada al candidato de la Concertación, independientemente de la persona de que esta coalición de partidos llevase como candidato. Este pronóstico se basaba en los excelentes resultados electorales obtenidos por la coalición de gobierno durante las elecciones presidenciales del 1989 y del 1993 cuando Patricio Aylwin y Eduardo Frei Ruíz-Tagle ganaron fácilmente las elecciones en primera ronda con respectivamene el 55,2 y el 57,9 de los votos. A lo anterior se agregaba el hecho de que desde 1990 la oposición de derecha se había mantenido extremadamente dividida, no logrando así convertirse en una seria amenaza electoral para las fuerzas de la Concertación. De esta manera, cuando Ricardo Lagos ganó las 'primarias' de la Concertación el 30 de mayo de 1999 frente a su contrincante Andrés Zaldívar, su victoria en los comicios presidenciales de diciembre del 1999 se consideraba garantizada. Sin embargo, la necesidad de realizar estas primarias a sólo 7 meses de las elecciones presidenciales afectó negativamente el grado de unidad y cohesión de la coalición de gobierno. A saber, la lucha entre Lagos y Zaldívar por la candidatura a la presidencia produjo una serie de confrontaciones inevitables entre socialistas y democratacristianos, las cuales no desaparecieron automáticamente tras el triunfo de Lagos en mayo de 1999.

Entre la victoria de Lagos en las primarias de mayo y el día de la elección en diciembre la popularidad de Joaquín Lavín aumentó fuertemente, al punto de que al final tenía una chance real de ganar los comicios. A pesar de que Lavín no logró ganar las elecciones, las elecciones de 1999-2000 dejaron en claro de que por primera vez desde la restauración democrática en 1990 la derecha chilena se había convertido en una opción real de gobierno en Chile (véase Silva, 1991; Angell, 2005).

Pienso que las grandes dificultades que tuvo que vencer Lagos para ganar la presidencia y el escaso margen de diferencia que logró ante su rival, ayudó a condicionar en gran medida la actitud que él posteriormente adoptaría con respecto a la presencia de grupos tecnocráticos en su gobierno. En primer lugar, Lagos sabía que su nombre y persona creaba grandes temores en el seno de la derecha política y de las élites económicas y financieras del país, como se haría evidente en los últimos meses de la campaña. En caso de ganar, Lagos sería el primer presidente de origen socialista desde la dramática experiencia de Salvador Allende a comienzos de los años 1970s. Su candidatura era incluso problemática ante importantes sectores de la Democracia Cristiana que no sólo compartían los temores de sacar elegido a un presidente socialista, sino que además una parte no despreciable de ellos se sentía atraído y representado por el discurso modernizante, tecnocrático y aparentemente apolítico levantado por Joaquín Lavín (cf. Silva, 2004).Y efectivamente tras las elecciones se pudo confirmar que mucha gente que en el pasado había votado por Aylwin y Frei había traspasado su apoyo al candidato de la derecha. 
De allí que Lagos estaba obligado a dar un mensaje de tranquilidad al electorado, para que tuviera la certeza de que él no transformaría el modelo económico y que tendría muchos elementos de continuidad con los dos gobiernos concertacionistas anteriores. De esta manera, Lagos tenía que demostrar que poseía los conocimientos necesarios para dar una buena conducción a la economía. Como señala Valdivieso "Lagos debió acentuar sus dones tecnocrático-empresariales, abandonando parte importante del discurso más tradicional, republicano, en el último período pre-electoral y durante el período que corre desde primera a segunda vuelta de las elecciones" (2002: 6). Así, tal como Lavín hacía alarde de que poseía una maestría en economía de la Universidad de Chicago, los encargados de la propaganda concertacionista tendrían que sacar a relucir la amplia experiencia académica e intelectual de Lagos: y papeles no le faltaban. Lagos había trabajado en la Facultad de Economía de la Universidad de Chile, llegando a ser secretario general de esta casa de Estudios, para luego pasar a trabajar como investigador y consultor de diversos organismos de prestigio internacional, tales como FLACSO, CEPAL, PNUD y la UNESCO. Durante su exilio trabajó como profesor invitado en la Universidad de Duke, en donde sacó un doctorado en economía. Además, es importante recalcar que en la segunda vuelta Lagos quedó muy comprometido con Soledad Alvear, la popular Ministra de Justicia de Frei quién renunció a su puesto para poner toda su popularidad al servicio de la candidatura de Lagos, como su jefa de campaña. Todo esto indicaba que Lagos estaría obligado a ser condescendiente con la Democracia Cristiana en la formación de su gabinete pero también que no podría darle un seño demasiado izquierdizante a su gobierno.

En los hechos Lagos era esencialmente un político con una fuerte orientación académica e intelectual pero que quería darle a su gobierno la imagen de 'hacedor', que desarrolló durante el gobierno de Frei como Ministro de Obras Públicas. El estilo de Lagos será una combinación de hombre pragmático de acción (poniendo plazos a sus ministros para lograr objetivos determinados), ${ }^{3}$ pero a la vez hombre de orientación de estadista, de pensar Chile en el futuro y fascinado con la idea del bicentenario a celebrarse en 2010.

Además, es importante tener en cuenta que se trataba de un economista más bien ligado a las viejas corrientes estructuralistas-cepalianas de los 1950s y 1960s. Es decir, poseía poca afinidad intelectual con las versiones más tecnocratizadas y 'manageriales' de los últimos tiempos que se enseñan en las universidades chilenas y norteamericanas, que sí habían formado e influenciado a muchos jóvenes economistas que participaban en los gobiernos de la Concertación. Esto se reflejaba en el slogan que utilizó para la primera vuelta, 'crecimiento con igualdad', una frase muy cepaliana que se apartaba del acento explícito puesto por Frei en la modernización

\footnotetext{
Siendo el caso más emblemático el nombramiento de Michelle Bachelet como Ministra de Salud, dándole públicamente la tarea de eliminar las colas en los consultorios médicos en tres meses. El buen desempeño de la ministra le daría gran notoriedad pública y popularidad, lo cual constituyó el comienzo de su camino hacia la presidencia.
} 
y que inquietó mucho a los sectores empresariales, ya que lo de 'igualdad' podía significar transformar radicalmente la distribución del ingreso en el país a través de aumentos de las cargas impositivas.

Lagos siempre mantendría hasta el término de su gobierno una posición ambigua ante la tecnocracia. ${ }^{4}$ Como Ministro de Obras Públicas convivió directamente con ellos, ya que dicho ministerio es un nido de ingenieros y Lagos hizo uso de la idea de ser hombre que hace cosas, emprendedor (inaugurando puentes y carreteras, etc.), lo cual le sirvió mucho para su campaña posterior. Lagos fue además bastante cuidadoso en no tomar abiertamente partido en el debate entre 'autocomplacientes' y ‘autoflagelantes' que se generó a partir de 1998 ya que sabía que esto podría ser fatal para sus pretensiones presidenciales, ya que necesitaría del apoyo de ambos sectores. $^{5}$

En la conformación de su gabinete, Lagos mostró elementos de continuidad y de cambio respecto al gobierno anterior. De continuidad ya que heredó algunas figuras que también habían sido ministros en el gobierno de Frei pero también de cambio ya que nombró como ministras a seis mujeres. Como señala Navia (2004: 258-9), una revisión de los ministros de su primer gabinete muestra que Lagos no favoreció la meritocracia sino que más bien expresa un tradicional 'cuoteo' político. Asimismo la integración de 'caras nuevas' obedecerían a necesidades y acomodos entre los partidos políticos. Este es el caso, por ejemplo, del nombramiento de Mariana Aylwin (Ministra de Educación e hija del ex-mandatario) y de Alejandra Krauss (Ministra de Planificación del Gobierno de Lagos hija

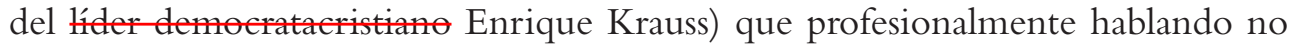
eran las personas más idóneas para ocupar dichas carteras. Sin embargo, este cuoteo era más bien para apaciguar los ánimos entre los partidos de la Concertación y no constituía una señal de que Lagos gobernaría junto a los partidos. Si bien Lagos era militante del PPD, nunca se proyectó como un hombre de partido y cuando organizó su campaña presidencial no lo hizo desde los partidos sino desde el think-tank 'Fundación siglo 21' que creó especialmente para este propósito. ${ }^{6}$

También llama la atención la amplia presencia de ministros con un entrena-

\footnotetext{
Sólo tras su mandato expresaría abiertamente su desaprobación de la tecnocracia. Así, en su discurso de apertura de la Escuela de Gobierno y Gestión Pública de la Universidad Alberto Hurtado en julio de 2006, Lagos criticó duramente al 'tecnocratismo' en la toma de decisiones. Allí insistiría que "se deben dejar atrás temas como el tecnocratismo y creer que la toma de decisiones es tarea de los tecnócratas y no de representantes de un país.(..) El técnico es esencial para introducir realismo pero en último término la definición la toma el político. (..) En la medida de que exista una visión integrada de cómo crear e implementar las políticas públicas, los encargados de gobernar tendrán un camino claro para enfrentar a la demagogia, porque sea usted tecnócrata o sea usted demagogo, ambos son igualmente peligrosos", La Tercera, 25 de julio de 2006.

Sin embargo, es muy decidor que varios de sus más cercanos colaboradores durante su gobierno habían suscrito en 1998 el documento autoflagelante 'La gente también tiene la razón', como es el caso de Guillermo Campero, Eugenio Lahera y Francisco Vidal.

Llama la atención que en dicha fundación Lagos atrajo principalmente a sociólogos y cientistas políticos de perfil humanista y crítico, y sólo unos escasos economistas de perfil no tecnocrático.
} 
miento profesional en derecho (ver cuadro 7.3), lo que estaría indicando que Lagos privilegió desde un primer momento un gabinete más político que técnico. Esto quedaba reflejado en el nombramiento de José Miguel Insulza como Ministro del Interior, que adquiría en los medios de comunicación el nombre de 'Panzer' por su gran fortaleza política y su reconocida habilidad negociadora. A pesar de esto, Lagos continuó la tradición ya asentada en los dos gobiernos anteriores de dejar el comando de la economía en manos de economistas de prestigio. El nuevo presidente sabía que en vista de las muchas aprensiones existentes sobre sus verdaderas intensiones en el terreno económico, debía dar una fuerte señal a la comunidad económica y financiera local e internacional de que el comando de la economía estaría en buenas manos. De esta manera, nombraría a Nicolás Eyzaguirre como Ministro de Hacienda. Comenzó en la CEPAL en los 1980s y luego pasó al Banco Central para posteriormente pasar a cursar estudios de postgrado en la Universidad de Harvard. Al momento de su nombramiento era uno de los directores ejecutivos del Fondo Monetario Internacional. Eyzaguirre es un tecnócrata 'atípico', ya que posee un pasado de izquierda, habiendo militado en algún momento de su vida en el Partido Comunista. Además, se caracterizaba por poseer un buen olfato político y por ser muy dado a la vida bohemia y a la música folklórica. Todo esto, junto a su manera sencilla y familiar de hablar y su excelente sentido del humor le facilitó enormemente su llegada a la gente durante el gobierno de Lagos. ${ }^{7}$ Lagos nombraría como Ministro de Economía, Energía y Minería al joven economista José de Gregorio. Este tecnócrata 'pura sangre' había sido coordinador de políticas macroeconómicas del Ministerio de Hacienda bajo Frei y estaba en posesión de un doctorado en economía en el MIT. Al momento de su nombramiento, se desempeñaba como profesor visitante de economía en la Universidad de California. ${ }^{8}$

Junto a Eyzaguirre y De Gregorio, Lagos incluiría entre sus colaboradores con perfil tecnocrático a Álvaro García (de la presidencia), Mario Marcel (Presupuesto) y Claudio Orrego (Vivienda).

Sin embargo, Lagos desde un primer momento no concederá grandes libertades y autonomía a sus ministros. Al contrario de Frei quien dio mucho espacio a sus colaboradores, Lagos se caracterizará por poseer un estilo político más autoritario y controlador. Según muchos analistas esto estaría relacionado al fuerte carácter del presidente y a su empeño de hacer un gobierno que pasara definitivamente a la historia como uno de los mejores de la Concertación. Otros van incluso más lejos e indican que el marcado egocentrismo y soberbia que caracterizaría la persona-

Al finalizar el gobierno de Lagos, Eyzaguirre se encontraba entre los ministros más populares y en un momento su nombre fue considerado como 'presidenciable' para los comicios del 2009.

8 La prensa comenzaría a especular si su perfil extremadamente técnico y su falta de experiencia política y partidaria no se convertiría en una gran desventaja en su funcionamiento. Así en una columna política se comentaba: "El nuevo puesto que lo espera como triministro no será nada de fácil (..). Se le reconoce gran capacidad para sacar adelante los desafíos de la cartera, ...pero su calidad de tecnócrata y de poca vida partidaria también le pueden jugar en contra”, 'El perfil del nuevo 'superministro', La Tercera, 1 de febrero de 2000. 
Estilos Políticos y Orientación TeCnocrática bajo los Gobiernos de Lagos y Bachelet / Patricio Silva

lidad de Lagos le habría impedido haber jugado el rol de director de orquesta en lugar de haber querido tocar cada uno de los instrumentos (véase Navia, 2004).

De hecho Lagos se proyectará por sobre los partidos políticos que conformaban la Concertación y tratará de levantar una imagen de estadista de prestigio internacional en medio de sus pares sudamericanos y a nivel mundial. Al cabo de unos años en el gobierno, varios analistas políticos lo empezarán a comparar con el estilo casi monárquico que caracterizaría al antiguo primer ministro francés, François Mitterand. ${ }^{9}$

\section{Cuadro 1:}

\section{Miembros del primer gabinete de Lagos: Credenciales profesionales}

$\begin{array}{lll}\text { José Miguel Insulza } & \text { Ministro del Interior } & \text { Abogado } \\ \text { Soledad Alvear } & \text { Ministra de Relaciones Exteriores } & \text { Abogada } \\ \text { Mario Fernández } & \text { Ministro de Defensa } & \text { Abogado } \\ \text { Nicolás Eyzaguirre } & \text { Ministro de Hacienda } & \text { Economista } \\ \text { Alvaro García } & \text { Secretario General de la Presidencia } & \text { Economista } \\ \text { Claudio Huepe } & \text { Secretario General de Gobierno } & \text { Abogado } \\ \text { José de Gregorio } & \text { Ministro de Economía \& Energía } & \text { Economista } \\ \text { Alejandra Krauss } & \text { Ministerio de Planificación } & \text { Abogado } \\ \text { Mariana Aylwin } & \text { Ministra de Educación } & \text { Profesora } \\ \text { José Antonio Gómez } & \text { Ministro de Justicia } & \text { Abogado } \\ \text { Ricardo Solari } & \text { Ministro del Trabajo } & \text { Economista } \\ \text { Carlos Cruz } & \text { Ministro de Obras Públicas, } & \text { Economista } \\ & \text { Transporte y Telecomunicaciones } & \\ \text { Michelle Bachelet } & \text { Ministra de Salud } & \text { Médico } \\ \text { Claudio Orrego } & \text { Ministro de Vivienda } & \text { Abogado } \\ \text { Jaime Campos } & \text { Ministro de Agricultura } & \text { Abogado } \\ \text { Alfonso Dualto } & \text { Ministro de Minería } & \text { Ingeniero } \\ \text { Adriana Delpiano } & \text { Servicio Nacional de la Mujer } & \text { Asistente social } \\ \text { José Weinstein } & \text { Ministro de Cultura } & \text { Sociólogo }\end{array}$

Su perfil más bien intelectual que técnico, le hacía desconfiar de los sectores tecnocráticos. Posiblemente Lagos también sacó lecciones de su experiencia como ministro en el gabinete de Frei Ruiz-Tagle. Una de las mayores críticas que tuvo su administración es que el presidente no daba conducción central lo que generaba desorden y que no paró a tiempo la lucha entre tecnócratas y políticos al interior de su gobierno. Además, durante el gobierno de Frei no hubo seguimiento sistemático de por quién, como y cuando se realizaban las tareas de los ministros.

Lagos optó por establecer una estructura más parecida a la norteamericana en donde un grupo de consejeros cercanos o staff presidencial, los miembros del llama- 
do 'kitchen cabinet', lo aconsejarían desde cerca y monitorizarían lo que hacían los ministros para ordenar la acción del gobierno. ${ }^{10}$ Así nacería el mítico 'segundo piso' del Palacio de la Moneda, en donde se encontraban las oficinas de sus principales asesores. Allí residían sus consejeros, entre los que se encontraban Ernesto Ottone, Agustín Squella, Guillermo Campero, Carlos Vergara y Javier Martínez; ${ }^{11}$ amigos probos del presidente que se caracterizan por poseer un perfil político-intelectual. La mayoría profesaba la sociología y fueron profesionales que durante al dictadura operaron desde diversos institutos de investigación privados, o desde FLACSO o la CEPAL, analizando la realidad social y política del país y que ayudaron a articular las políticas de reemplazo ante un eventual fin de la dictadura (véase Puryear, 1994). Este es el caso de Guillermo Campero, reconocido sociólogo experto en relaciones laborales y profundo conocedor de las organizaciones empresariales quién durante la dictadura hizo estudios de postgrado en la EHHS de París y de regreso en Chile trabajó en el Instituto Latinoamericano de Estudios Transnacionales (ILET). Otro de los miembros del Comité de Asesores sería el destacado sociólogo Javier Martínez que trabajó en la Corporación de Estudios Sociales y de Educación (SUR) y quién ha escrito ampliamente sobre los cambios en las relaciones sociales en Chile como producto de las transformaciones económicas y culturales producidas por el sistema neoliberal.

También entre sus más cercanos asesores se encontraba Eugenio Lahera quién ya desde comienzos de los 1980s había trabajado junto a Ricardo Lagos en diversas consultorías. Además ha sido editor de la Revista de la CEPAL y colaboró muy de cerca junto a Lagos durante las dos vueltas de la campaña presidencial y en la Fundación Chile 21 de la cual fue su director. Era el único abogado del comité de asesores cercanos, con un doctorado en Asuntos Públicos de la Universidad de Princeton.

El jefe del grupo de asesores de Lagos era el sociólogo Ernesto Ottone que posee un doctorado en ciencias políticas por la Universidad de París. En su juventud fue dirigente del Partido Comunista y mantiene una vieja amistad personal con Lagos y un pasado común en la CEPAL, de la cual Ottone fue su secretario general. ${ }^{12}$

El Comité de Asesores de Lagos optó por tomar desde un comienzo una actitud de bajo perfil que incluía evitar la publicidad y la entrega de entrevistas o declaraciones públicas. Si bien poco o nada oiría la opinión pública de estos asesores, al interior del gabinete su presencia se haría sentir desde un primer momento y con fuerza.

\footnotetext{
$10 \quad$ Lagos ya había lanzado la idea de conformar este comité de asesores entre sus principales colaboradores durante la campaña presidencial.Véase ‘Traje a la medida de Lagos', Que Pasa, 24 de enero de 2000.

$11 \quad$ Además de su background sociológico y generacional, y que algunos de ellos estudiaron en París, los unía el curioso hecho de que todos los sociólogos nombrados eran oriundos de la ciudad de Valparaíso y fanáticos del club Wanderers. Ver ‘¿Que significa ser wanderino?: verde que te quiero verde', El Mercurio de Valparaíso, 29 de abril de 2001.

12 Ver 'Ernesto Ottone: el ocaso del consejero', Qué Pasa, 27 de agosto de 2005.
} 
Como señala Huneeus, durante la administración Lagos la relación de los miembros del comité de asesores con los ministros no fue fácil. A menudo el presidente se hacía acompañar con algunos de sus asesores en conversaciones con algún ministro quien tomaba notas de lo acordado. ${ }^{13}$ De hecho, una de las principales funciones que le otorgó Lagos a su Comité de Asesores sería oficiar de órgano fiscalizador de las tareas asignadas a cada ministerio. Además, ellos entregaban información y análisis estratégicos al presidente Lagos y debían ser siempre consultados por los demás ministros y funcionarios del gobierno en temas importantes.

Si bien Lagos tendrá bien controlada a la tecnocracia en el plano interno, durante su gobierno se dio un fuerte auge tecnocrático en el plano de la política comercial internacional. El Ministerio de Relaciones Exteriores experimentará un fuerte proceso de modernización y profesionalización, que se hacia necesario para poder formular y negociar una serie de acuerdos de libre comercio con países de Norteamérica, Europa y Asia que se concretizaron durante el gobierno de Lagos. Esto se concreta en el fortalecimiento de la Dirección de Asuntos Económicos Internacionales dentro de la cancillería en donde un batallón de jóvenes economistas se encargaría de formular las estrategias comerciales de Chile y de representar al país en comisiones especializadas de diversos organismos internacionales, tales como la APEC. ${ }^{14}$

\section{Bachelet: ¿Tecnocracia con Participación Ciudadana?}

En la fase final del gobierno de Lagos se comenzó a generar al interior de la Concertación un clima de incertidumbre y vacilación respecto al futuro del conglomerado gobernante. Así muchos comenzaban a hacerse la idea que no habría un cuarto gobierno de la Concertación. Este escenario quedaría plasmado en el documento 'La ceremonia del Adiós' que escribiera el sociólogo socialista Antonio Cortés Terzi y que fuera difundido en forma reservada al interior de círculos concertacionistas. A esto se unían las críticas encubiertas a Lagos por haberse preocupado en demasía por fortalecer su popularidad personal, pero haber hecho poco o nada en transmitir esa popularidad a la coalición de gobierno que lo había llevado al poder.

Simultáneamente, comenzó a crecer el convencimiento en la oposición de derecha de que, esta vez, su candidato Joaquín Lavín derrotaría a la coalición de gobierno en las elecciones de diciembre de 2005. La tesis de Lavín, de que cualquier candidato de la Concertación sólo representaría 'más de lo mismo' y que él, al contrario, era la

\footnotetext{
13 Carlos Huneeus, 'Los asesores presidenciales', La Tercera, 2 de julio de 2006.

$14 \quad$ Por ejemplo, me parece muy decidor la entrevista de Ricardo Lagos Weber (al hablar de como su experiencia como negociador en el extranjero podría servir en sus planes de entrar en la política nacional) (La Tercera, 26 september 2004) Allí afirma: "Se ha hecho un gran trabajo para insertar a Chile en el mundo, pero la pega que viene por delante es casi más grande que los acuerdos firmados. Ahí está mi vínculo con la política. Necesitamos políticas públicas que orienten el desarrollo futuro de Chile.Y considero que hay que profesionalizar aún más el Parlamento. Aportar miradas de gente que venga más de la tecnocracia y pueda transferir su experiencia al mundo político. Humildemente, creo que uno puede hacer una contribución, darle un énfasis distinto, un frescor a la política."
} 
encarnación del cambio, comenzaba a calar firme en la opinión pública. Sin embargo, el surgimiento a fines del 2004 de dos mujeres como pre-candidatas presidenciales del bloque gobernante, comenzaría a revertir la suerte de Lavín. El surgimiento de Soledad Alvear y de Michele Bachelet como posible futuras líderes del país representaba efectivamente un cambio realmente revolucionario en la política chilena, generando gran interés en los medios de comunicación locales e internacionales y creando grandes expectativas entre la población.

El duelo entre Alvear y Bachelet para asumir la representación de la Concertación en las elecciones presidenciales, haría revivir los mismos roces y desgastes entre democratacristianos y socialistas que se observaron durante las primarias entre Andrés Zaldívar y Ricardo Lagos en 1989. Esta vez, sin embargo, la eventualidad de un triunfo de la abanderada socialista creaba mucho más asperezas al interior de la Democracia Cristiana que la vez anterior. Por un lado, el eventual triunfo de Bachelet significaba que un candidato socialista representaría por segunda vez consecutiva a la coalición de gobierno, lo cual a los democratacristianos les era extremadamente dificil de aceptar. Además, Bachelet representaba a la llamada 'nueva izquierda', el ala más dura dentro del partido socialista, lo cual generaba aprensiones en las cúpulas DC respecto a la naturaleza político-ideológica de un eventual cuarto gobierno concertacionista bajo su conducción.

Lo que es importante señalar aquí es el hecho que la candidatura de Bachelet no fue una decisión ni de Lagos ni de las dirigencias socialistas, sino que más bien se impuso por la popularidad de la candidata ante la opinión pública. Ella tuvo un excelente desempeño como Ministra de Salud y de Defensa bajo el gobierno de Lagos y conquistó a la ciudadanía por su gran simpatía, por su actitud alegre, por su aporte a la reconciliación entre los chilenos y por llegar a la gente con un lenguaje simple y popular. Así, fueron los medios de comunicación los que la fueron identificando como una potencial candidata presidencial, mientras que la cúpula de su partido, los llamados 'barones socialistas', dudaron por mucho tiempo en apoyar una candidatura que no se había gestado al interior del partido. ${ }^{15}$ De esta manera, la campaña de Bachelet no sólo encontrará retractores en la Democracia Cristiana sino que además dentro de su propio partido que veían en Bachelet un peligro por el poco o nulo grado de influencia que podrían tener las dirigencias partidistas en su eventual gobierno. El retiro de Soledad Alvear de la carrera a la presidencia en mayo de 2005 dejó el camino libre a Bachelet para representar la Concertación en las elecciones de diciembre de 2005.

Bachelet levantó al comienzo de su campaña un discurso anti-tecnocrático que, de salir elegida en las elecciones de diciembre, hacían presagiar momentos difíciles para la $15 \quad$ Como dijera Andrés Velasco sin tapujos en una entrevista en octubre de 2005: "Michelle Bachelet no es una candidata que está ahí gracias al establishment, sino que está ahí a pesar del establishment de la Concertación. Si las estructuras partidarias hubiesen tenido poder de veto al momento de nominar un candidato presidencial, Bachelet no sería la candidata", La Nación, 9 de octubre de 2005. 
tecnoburocracia estatal. ${ }^{16}$ En parte, la acentuación de su discurso anti-tecnocrático estaba dirigido en contra de su rival de derecha, Joaquín Lavin, quien era la personificación del tecnócrata neoliberal de la escuela de Chicago. A lo anterior se agrega el hecho que en mayo de 2005 surgía inesperadamente desde la derecha otra candidatura presidencial. Se trataba del economista Sebastián Piñera quién también tenía antecedentes tecnocráticos, contra los cuales también tenía que marcar públicamente distancia.

La campaña de Bachelet como pre-candidata para representar a la concertación tenía el muy decidor lema de 'no a los tecnócratas, sí a la gente'. Tanto la vocera de su comando, la diputada socialista Carolina Toha, como el dirigente socialista Ricardo Solari, uno de sus más cercanos asesores, ejercían fuerte influencia en Bachelet respecto a los aspectos nocivos de la tecnocracia, con el objetivo de fortalecer la participación ciudadana en las políticas públicas. ${ }^{17}$

Es interesante hacer notar que, tal como el informe sobre desarrollo humano del PNUD del 1998 tuvo un impacto importante en la controversia entre autoflagelantes y autocomplacientes en 1998, el informe del PNUD sobre el poder en Chile, aparecido en enero del 2005, ejercería una fuerte influencia al interior del comando de Bachelet. ${ }^{18}$ En dicho informe se criticaba el carácter tecnocrático de la elite estatal y se hace un urgente llamado a fortalecer los mecanismos de participación ciudadana en Chile.

"Mientras unos se orientan hacia la construcción de un proyecto colectivo que integre a la sociedad a través de una democracia más abierta, otros adhieren a una visión orientada hacia los proyectos individuales y a una conducción más tecnocrática. (..) El reto parece estar en el tránsito desde un modelo de democracia representativa a uno participativo, en el cual los actores sociales ajenos al Estado y la sociedad política puedan "hacer política" desde la sociedad civil, participando y colaborando en la gestión de lo público" (PNUD, 2005: 208, 242).

A partir de mediados de 2005 Bachelet y su comando comenzará a fortalecer su discurso en pro de la participación ciudadana, lo cual significaba un cambio notable

\footnotetext{
16 En un debate improvisado Bachelet afirmaba:"apuesto a una política distinta, a una democracia más participativa, que en las políticas públicas haya más capacidad, evolución y una participación mucho más allá que un grupo de tecnócratas", La Nación, 3 de agosto de 2005.

Así, en el ensayo escrito en 1996 sobre la administración del Estado, ambos concluían que:"Satisfacer las nuevas exigencias de las instituciones públicas en el ámbito de la gestión con la pura especialización técnica es una simplificación ilusoria. (..) Las limitaciones de la tecnocracia en el ámbito de la gerencia pública son evidentes (..) Ésta no da respuesta a problemas que requieren cumplimiento de compromisos democráticos y consideración de factores de tipo político. Además, el buen desenvolvimiento de los especialistas en el Estado resulta insuficiente si no está acompañado por la toma de contacto con la realidad social, con las preocupaciones y percepciones de los ciudadanos" (Toha y Solari, 1996: 15).

18 "La intelligentsia del comando estudia y cita como una Biblia de Jerusalén el informe "El poder: para qué y para quién?' del programa de Naciones Unidas para el Desarrollo”, El Mostrador, 25 de julio de 2005.Ver además, 'El baile de los que mandan', La Nación, 16 de enero de 2005.
} 
de lo que había sido hasta ese momento la posición de la Concertación respecto a la participación. Hasta entonces, se había privilegiado la consolidación de las estructuras e instituciones democráticas y el principio de la democracia representativa pero no el de la democracia participativa. ${ }^{19}$ Lo interesante de este discurso es que introduce con fuerza en la escena política la figura de 'la ciudadanía', la cual pasaría a ser privilegiada a nivel discursivo no sólo en detrimento de los estamentos tecnocráticos, sino que también de los partidos políticos. Bachelet parecía prescindir cada vez más del apoyo de los partidos políticos de la Concertación, mientras que el presidente Lagos y sus ministros se mantuvieron prácticamente inactivos durante toda la campaña hasta la elección de diciembre de 2005. La adopción de esta estrategia suprapartidista por parte de Bachelet le traería cada vez más roces con los miembros de la dirigencia de los partidos políticos que formaban la Concertación quienes veían con estupor que no podían ejercer mucha influencia en los pasos que adoptaba la candidata y su comando. Esto quedaría en evidencia cuando Bachelet, tras visitar al primer ministro español Rodríguez Zapatero en julio de 2005, declaraba súbitamente que ella también aplicaría una estricta paridad de género en la elección de sus ministros y otros altos funcionarios. Esta medida, significaba que la dirigencia concertacionista, que prácticamente en su totalidad era masculina, perdía de un plumazo el acceso a la mitad de los puestos claves en un futuro gobierno de esta coalición de gobierno. A eso se sumaría el anuncio de Bachelet al final de la campaña que en su gobierno 'nadie se repetirá el plato', aludiendo a que no habría continuismo en el personal de gobierno ya que no llamaría a ministros y altos funcionarios que habían colaborado con el gobierno anterior, a formar parte de su gabinete. Con ambas medidas, Bachelet quería hacer realidad su promesa de abrir el paso a 'caras nuevas' para hacer posible un aggiornamento generacional dentro de la Concertación.

Pero Bachelet tendría que solucionar un par de dificiles problemas antes de poder conformar un futuro gobierno, en caso de salir victoriosa en las elecciones presidenciales. ¿Cómo lograr la confianza y el apoyo de un amplio sector de la ciudadanía y del empresariado en general que veía con cierto recelo sus credenciales demasiado izquierdistas? Y ¿dónde reclutar a sus colaboradores más cercanos para su futuro gobierno si se había optado concientemente por seguir una estrategia suprapartidaria? Bachelet encontró la solución de estos problemas en su decisión de establecer una alianza estratégica tácita con el think tank 'Expansiva', un centro de ideas que reunía a un amplio grupo de jóvenes pensadores, intelectuales y tecnócratas de inspiración liberal pero de orientación probadamente concertacionista. Al igual que Lagos, Bachelet dejaría en claro que a pesar de su orientación socialista, la política económica en su eventual gobierno quedaría en manos de prestigiosos economistas de corte liberal que seguirían desarrollando el modelo económico sustentado hasta

$19 \quad$ La crítica y la demanda de una democracia más participativa y directa había sido hasta entonces una bandera de lucha que se limitaba principalmente a la izquierda extraparlamentaria y a algunos sectores de los 'autoflagelantes' de la Concertación, sobretodo procedentes del Partido Socialista. 
entonces. De allí que comenzaría a asistir a diversos foros económicos, acompañada por economistas de Expansiva.

Los orígenes de Expansiva se encuentran en las aulas de la Universidad de Harvard, en donde en enero de 2002 se realizó, por iniciativa del economista chileno Andrés Velasco, una reunión de alrededor cuarenta jóvenes académicos y profesionales chilenos, entre ellos economistas, politólogos y sociólogos que trabajaban en varias universidades norteamericanas para pensar sobre 'El Chile que viene'. Esta reunión se repetiría un año más tarde, esta vez a las alturas del Cerro Nevado, frente de Santiago, la cual suscitaría gran atención mediática. ${ }^{20}$ Allí se consolidó la idea de crear 'Expansiva', un think tank de jóvenes profesionales que querían aportar con ideas para hacer posible la formulación de mejores políticas públicas para el país. Es una organización moderna, sin sede fisica y poseyendo como herramienta principal un sitio web en donde los miembros publican sus papers sobre los más variados temas y áreas de la realidad nacional. Su líder, Andrés Velasco posee un abultado currículo. Poseedor de un doctorado en economía en la Universidad de Harvard,Velasco había sido director del Departamento de Estudios Latinoamericanos de la Universidad de Columbia y partir de 1996 se le nombraría profesor vitalicio en la cátedra de economía de la Universidad de Harvard. Sus inicios profesionales como economista los hizo en los años 1980s en CIEPLAN en donde trabajó muy de cerca con Alejandro Foxley, su director.Tras la restauración democrática en 1990, siguió a Foxley hacia el Ministerio de Hacienda, en donde se desempeñó como coordinador de finanzas internacionales. Durante la formación del gabinete del Presidente Lagos el nombre de Andrés Velasco circuló como su posible Ministro de Hacienda pero al final la elección de Lagos recaería en Nicolás Eyzaguirre. A partir de entonces, se dedicaría de lleno a la actividad académica en Estados Unidos. Velasco poseía un perfil completamente tecnocrático, se autodefinía como independiente y defendía abiertamente el libre mercado y la búsqueda de excelencia técnica en la formulación y aplicación de las políticas públicas. ${ }^{21}$

Expansiva tendrá en la figura de Jorge Marshall a otro 'monje' de CIEPLAN entre sus miembros más importantes (véase Silva, 1991). Este doctor en economía por la Universidad de Harvard, presidente de Expansiva desde marzo de 2006, se desempeñó bajo el gobierno de Aylwin como subsecretario de economía y luego como Ministro de economía y es actualmente Director del BancoEstado. También se unirían a Expansiva los miembros más destacados del grupo de tecnócratas deno-

Véase por ejemplo, 'New Kids en el Poder', La Nación, 2 de febrero de 2003 y 'Shiny Happy People', La Nación, 23 de febrero de 2003. Como sugieren ambos títulos, se subraya la formación norteamericana de la mayoría de estos jóvenes profesionales.

21 En un artículo de julio de 1997, Velasco hacía una abierta defensa de la tecnocracia. "La democracia moderna opera sobre dos principios: delegación y competencia. Delegamos a una élite ciertas decisiones, porque son técnicamente complejas, y es eficiente que los expertos dictaminen. Con ellos a cargo del tema, el resto de la ciudadanía puede irse tranquilamente de vacaciones (..). La democracia chilena es elitista, cerrada, tecnocrática, estéticamente impresentable, pero funciona.", La Tercera, 19 de julio de 1997. 
minados 'Top Ten' que había colaborado con el gobierno de Frei Ruiz-Tagle (Jorge Rosenblut, Pablo Halpern y Eduardo Bitrán). Jorge Rosenblut, que tras su salida del gobierno de Frei se había transformado en un exitoso empresario tanto en Chile como en Estados Unidos, se convertiría en un intermediario privilegiado entre Bachelet y el empresariado chileno, encargándose además de conseguir fondos para su campaña presidencial. ${ }^{22}$ Por su parte, Halpern regresaría a la escena nacional, al convertirse en el principal asesor mediático de la candidata. ${ }^{23}$ Finalmente, Eduardo Bitrán jugaría más adelante un rol destacado en el gobierno de Bachelet.

La emergencia de Expansiva como un referente de importancia para Bachelet significaba de hecho el retorno de los monjes de Cieplan y de los Top Ten al centro de gravitación político del país tras un período de 'enfriamiento' durante el sexenio de Lagos que los había distanciado de la esfera pública. Con esta elección, Bachelet además reinstauraba el principio de transversabilidad que había surgido durante el gobierno de Aylwin y que había sido prácticamente abandonado por la administración de Frei Ruiz-Tagle.

El acercamiento de Bachelet a los dirigentes liberales de Expansiva desde comienzos de 2005 fue seguido con mucho recelo por los dirigentes de la Concertación y en particular, por los miembros del think tank socialista 'Fundación Chile 21', dirigida por el economista, ex ministro de economía y posterior senador por el PS, Carlos Ominani. ${ }^{24}$ Esta fundación asociada al mundo PPD-PS había jugado un rol clave en la campaña presidencial de Ricardo Lagos en 1999 y había apostado a que Bachelet se apoyaría en ellos para elaborar su programa de gobierno, para luego fungir como nicho privilegiado de reclutamiento de expertos para su gobierno. Sin embargo, Bachelet parecía decidida a distanciarse lo máximo posible de las huestes laguistas y de las estructuras partidistas. En todo caso, la pugna entre los think tanks Expansiva y Chile 21 reproduciría de una u otra manera la pugna entre los sectores 'autocomplacientes' y 'autoflagelantes' de la Concertación que se venía arrastrando desde 1998.

Pero ¿como conjugar su elección por los tecnócratas de Expansiva para articular su programa económico y de gobierno en general con su discurso anti-tecnocrático inicial? Pienso que la clave de esta contrariedad se encuentra en el hecho que Bachelet tomó conciencia de que quería lograr mucho en un período presidencial relativa-

\footnotetext{
22 Fue justamente Rosenblut quien organizó el encuentro que sostuvo Bachelet en Nueva York en enero de 2005 con altos ejecutivos del mundo financiero de grupos como J.P. Morgan y Citigroup para darles señales de tranquilidad y confianza respecto a su eventual conducción económica. Este era el primer viaje de Bachelet al extranjero en su condición de candidata presidencial.Véase 'El hombre de Bachelet en Miami', Qué Pasa, 26 de marzo de 2005 y 'El hombre de las platas de Bachelet', Que Pasa, 31 de diciembre de 2005.

23 Véase, 'Pablo Halpern: El regreso a las grandes ligas', Qué Pasa, 27 de agosto de 2005.

$24 \quad$ Véase 'Vínculos Bachelet-Expansiva generan anticuerpos en el PS', La Tercera, 27 de marzo de 2005. 'La pugna por el corazón y la mente de Bachelet', La Tercera, 3 de abril de 2005 y 'Pugna entre asesores de la candidata', La Tercera, 14 de mayo de 2005.
} 
mente corto. ${ }^{25}$ Para eso se hacía imprescindible el poseer un programa de gobierno bien delineado, con una clara estrategia económica y social y con la identificación de cuales serían las reformas más emblemáticas de su presidencia; todo esto, antes de asumir al poder en marzo de 2006. Al parecer, también se dio cuenta de que era posible reconciliar la presencia de una tecnocracia en su gobierno con su objetivo de fortalecer la participación ciudadana. Esto se hizo evidente en la manera como Bachelet, en su condición de pre-candidata, estructuró la confección de su programa de gobierno desde comienzos de enero de 2005. Para ello se constituyeron diversas comisiones de trabajo, en donde participaron académicos y expertos en cada materia, pero a las cuales también se invitó a figuras representativas de ciertos sectores y organizaciones de la sociedad civil. ${ }^{26}$ Ese sería el mismo estilo de trabajo que ella seguiría a partir de mayo de 2005, cuando definitivamente se convirtió en la candidata presidencial de la Concertación para los comicios de diciembre de ese año. Nuevamente optó por la creación de comisiones de trabajo a cargo de expertos, con cierta participación de sectores sociales.

Por otro lado, como producto de su experiencia en su exilio europeo, por su formación profesional como médico cirujano pero sobre todo por sus estudios de postgrado en asuntos militares en Washington en el período 1997-98, Bachelet estaba, en los hechos, mucho menos distante del universo tecnocrático de lo que se suponía.Además, su actitud aplicada, sacando siempre las mejores notas e intentando ser la mejor, y su reconocido pragmatismo y aterrizaje para abordar tareas y problemas, la puso desde un primer momento en buena sintonía con tecnócratas como Andrés Velasco y Jorge Marshall que poseen estilos de trabajo y modos de acción bastante afines. $^{27}$

Así tras las primera vuelta de las elecciones presidenciales el 11 de diciembre de 2005, en la que pasaría al balotaje junto a Sebastián Piñera, Bachelet presentaba públicamente a fines de ese mes su 'Plan 100 días: 36 compromisos'. En el mejor estilo tecnocrático, la candidata se comprometía a cumplir objetivos específicos en un período de tiempo preestablecido. Además, se hizo acompañar por un destacado elenco de economistas, entre los que se encontraban Andrés Velasco y Alejandro Foxley, quienes dieron un detallado recuento técnico-financiero sobre cuanto costará la aplicación del plan y cómo se financiarían las 36 medidas que se adoptarían en los primeros cien días de gobierno. En dicha ocasión, y refiriéndose con orgullo a la alta calidad profesional de los miembros del equipo técnico que formuló el plan de las 36 medidas, Bachelet concluía que "la Concertación, como ningún otro sector político,

\footnotetext{
$25 \quad$ Al contrario de Frei Ruiz-Tagle y de Lagos el congreso había acordado que el periodo presidencial a partir de ahora sólo duraría cuatro años (en lugar de seis).

Véase 'Los nuevos nombres y estilo de Bachelet', La Nación, 8 de enero de 2005.

Véase, “Como Andrés Velasco conquistó a Bachelet', Que Pasa, 4 de febrero de 2006. De esta manera, como sugiere Patricio Navia, "porque Bachelet privilegia el pragmatismo, prefiere las relaciones horizontales y quiere promover la inclusión, la diversidad y la participación, su estilo se acomoda fácilmente al que caracteriza a los tecnócratas formados en Estados Unidos”, “Los yankees de Bachelet', Qué Pasa, 11 de febrero de 2006.
} 
puede convocar a un grupo de tan altísima calificación", ${ }^{28}$

Pero la mayor sorpresa de Bachelet tan sólo vendría tras su triunfo en el balotaje del 15 de enero de 2006. Si bien la holgada diferencia que logró ante su contrincante Sebastián Piñera (53,5\% contra 46,5\%) ayudó a fortalecer su relativa autonomía ante los partidos de la Concertación, también es cierto que fue el aparataje partidista y el propio gobierno de Lagos el que se movilizó activamente entre la primera y la segunda vuelta para lograr el triunfo de la abanderada concertacionista. ${ }^{29}$ De allí que en círculos oficiales existía casi la seguridad de que Bachelet, al momento de definir los miembros del gabinete, no renegaría sus vínculos con los partidos de la coalición en general y con el socialismo concertacionista en particular. ${ }^{30}$

Bachelet mostraría total hermetismo en la configuración de su gabinete, manteniendo hasta el último minuto el suspenso respecto a quienes serían parte de su equipo de ministros. Su autonomía de los partidos políticos en la configuración de su gabinete fue de tal magnitud, que sólo minutos antes del anuncio oficial de su gabinete el 20 de enero de 2006, informó a los secretarios generales de dichas colectividades respecto a la lista de Ministros que enunciaría al país. Si bien estos últimos le habían hecho propuestas a la presidenta electa, ella prácticamente hizo caso omiso a dichas peticiones y presiones, presentando al final una nómina de ministros que dejó atónito a toda la elite política de la Concertación y al país en general. ${ }^{31}$

\section{Cuadro 2 Miembros de 'Expansiva' en el gobierno de Bachelet}

Nombre

Andrés Velasco*

Eduardo Bitran $\star \star$

Vivianne Blanlot

Karen Poniachik

\section{Cargo y credenciales académicas}

Ministro de Hacienda (PhD in Economics, Columbia University)

Ministro de Obras Públicas (PhD in Economics, University of Boston)

Ministra de Defensa (M.A. in Economics, American University)

Ministro de Minería y Energía (M.A. International Relations, Columbia University)

\footnotetext{
28 La Nación, 28 de diciembre de 2005.

29 Así por ejemplo, Lagos liberó a su experimentado Ministro de Educación, Sergio Bitar, para que tras la primera vuelta renunciara a su puesto y se pusiera a la cabeza de la campaña de Bachelet para la recta final.

30 En medio de la expectación sobre quién elegiría Bachelet, la mayoría de los analistas políticos, incluyendo a prestigiosos politólogos como Ricardo Israel y Carlos Huneeus, se inclinaban por que Bachelet finalmente no se desligaría de los partidos políticos, debido al activo y decisivo rol que jugaron en la campaña del balotaje. Véase ‘¿Innovará tanto con su estilo?', El Mercurio de Valparaíso, 17 de enero de 2006.

$31 \quad$ Así, uno de los principales periódicos titulaba la noticia del anuncio de la nómina ministerial con "El estilo de la Presidenta electa: Bachelet se desmarca de presión partidista', El Mercurio, 31 de enero de 2006. Según el sociólogo Eugenio Tironi, tras el anuncio de las designaciones ministeriales, los partidos políticos habían entrado en un 'estado de shock'.Véase entrevista en La Tercera, 2 de abril de 2006, 'Bachelet ha creado su propia transversalidad'.
} 
Estilos Políticos y Orientación Tecnocrática bajo los Gobiernos de Lagos y Bachelet / Patricio Silva

María Olivia Recart

Pilar Romaguera

Pablo Bello

Carlos Álvarez

Jean Jacques Duhart

Jorge Marshall*

Pilar Armanet

Luis Felipe Céspedes

Marcelo Tokman

Heidi Berner

Jorge Rodríguez

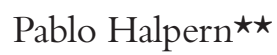

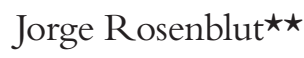

José Miguel Benavente

Cristóbal Aninat

Axel Christensen

Andrea Repetto*

Alfredo Joignant
Subsecretaría de Hacienda (M.A. in Economics, Universidad Humberto Hurtado)

Subsecretario de Educación ( $\mathrm{PhD}$ in Economics, Boston University)

Subsecretario de Comunicaciones (Economía, Universidad de Chile)

Vicepresidente ejecutivo de CODELCO. (M.A. in Public Administration, Harvard University)).

Gerente de innovación CODELCO (M.A. en

Administración pública, ENA- France)

Vicepresidente de BancoEstado ( $\mathrm{PhD}$ in Economics, University of Harvard)

Embassador to France (M.A. in Public Studies, Universidad de Chile)

Coordinador de políticas financieras, Ministerio de Hacienda (PhD in Economics, New York University).

Coordinador general de los conejeros de Ministro,

Ministerio de Hacienda (PhD. in Economics, University of California at Berkeley).

Coordinadora de la Dirección de Presupuesto (DIPRES) (M.A. in Public Administration, Harvard University).

Director del departamento de estudios de la Dirección de Presupuesto (DIPRES) (M.A. in Economics, Harvard University).

Principal consejero estratégico de la campaña presidencial de Bachelet (MBA in Kellogg School of Management, Northwestern University).

Contacto con la comunidad empresarial y consejero de presupuesto durante la campaña presidencial de Bachelet (M.A. in Public Administration, Harvard University).

Miembro del Consejo Nacional para la Innovación (ingeniero industrial, Universidad de Valparaíso).

Miembro de la Comisión Presidencial 'Boeninger' (sistema electoral binominal) (M.A. in Political Science, New York University).

Miembro de la Comisión Presidencial 'Marcel, (sistema de pensiones) (M.A. in Business Administration, Stanford University).

Miembra de la Comisión Presidencial 'Marcel' (sistema de pensiones) ( $\mathrm{PhD}$ in Economics, MIT).

Miembro de la Comisión Presidencial 'García' (reforma edu- 
Revista de Sociolocía 21 / 2007 Chile Hoy

Facultad de Ciencias Sociales - Universidad de Chile

cacional) ( $\mathrm{PhD}$ en ciencia política, Université de Paris I Pantheon-Sorbonne).

Carolina Toha Miembra de la Comisión Presidencial 'García' ( $\mathrm{PhD}$ en ciencia política, Università di Milano).

Alejandra Mizala Miembra de las comisiones presidenciales 'Marcel' y 'García' ( $\mathrm{PhD}$ in Economics, University of California at Berkeley).

Daniel Fernández Director ejecutivo de Televisón nacional de Chile (TVN) (Ingeniero civil, Universidad de Chile)

Bernardita Escobar Consejera del Ministro de Economía (MPhil in Economics, Cambridge University)

Luis Eduardo Bresciani Jefe de la División de Desarrollo Urbanístico del Ministerio

$\star$ Ex monjes de Cieplan. $\quad$ $\star \star$ Ex Top Ten. de Viviendav(M.A. in Urban Design, Harvard University).

Fuentes: Diversos periódicos y portales electrónicos institucionales.

La primera gran sorpresa fue que cumplió al pie de la letra su promesa de nombrar a la mitad de su gabinete con mujeres y de no nombrar personajes políticos demasiado fogueados. ${ }^{32}$ La gran mayoría de los miembros de su gabinete era efectivamente relativamente joven y poseía un marcado perfil técnico-profesional, muchos de ellos con estudios de postgrado en los Estados Unidos. ${ }^{33}$ Sin embargo, el factor más saliente de su gabinete, y el que creó una serie de debates al interior de los partidos de la Concertación y en los medios de comunicación, sería la fuerte presencia de miembros del think tank 'Expansiva' en el gabinete y en el resto del aparato de gobierno. ${ }^{34}$

La lista de los ministros de Expansiva era encabezada por Andrés Velasco, Ministro de Hacienda, que se convertía así en el nuevo hombre fuerte de la economía chilena. ${ }^{35}$ Bachelet también puso a miembros de Expansiva en dos ministerios de fuerte peso en Chile como lo son el Ministerio de Defensa, con Vivianne Blanlot y el Ministerio de Obras Públicas, dejándolo a cargo del ex ‘Top Ten’ Eduardo Bitrán. Expansiva también se apoderaría de varias subsecretarías y estará bien representado en una serie de comisiones especiales creadas por la Presidenta Bachelet (ver cuadro 2). Uno de los pocos puntos de unión entre el gobierno de Lagos y el de Bachelet sería

\footnotetext{
Tras la sorpresa de muchos, nombres de destacados líderes de la Concertación, como Sergio Bitar, José Antonio Viera-Gallo o Jorge Schaulsohn, que todos daban casi por contado como futuros ministros, no aparecerían finalmente en la lista de la Presidenta electa.

33 El alto nivel técnico del gabinete de Bachelet llamaría la atención a nivel internacional. Así, en la prensa argentina, en un artículo titulado, 'El gabinete más globalizado de América Latina', se subrayaba con entusiasmo que "un 70\% de los ministros nombrados por Bachelet habla inglés y la mayoría de ellos tienen doctorados de las universidades más importantes de Estados Unidos y Europa”. El artículo concluye que estas personas "no pasaron sus años de exilio en Estados Unidos y Europa llorando sobre sus dramas personales, sino preparándose para el futuro en algunas de las mejores universidades del mundo", La Nación de Buenos Aires, 11 de marzo de 2006.

$34 \quad$ Véase 'Nuevo grupo de pensamiento irrumpe en el poder: ¿Qué es Expansiva?', La Nación, 12 de febrero de 2006.

35 Esta designación causó mucho malestar en los círculos socialistas, quienes habían apoyado a la figura de Mario Marcel, otro talentoso jóven tecnócrata, poseedor de un PhD en economía en la Universidad de Cambridge y que había estado muy cercano a Bachelet durante la campaña.
} 
representado por la figura del hijo del ex Presidente, Ricardo Lagos Weber, quien sería nombrado Ministro Secretario General de Gobierno, siendo el vocero oficial de su gobierno hasta diciembre de 2007.

Bachelet exhibió su moderno estilo de gestión como jefe de gobierno ya al momento del juramento de los nuevos ministros a quienes, ante la sorpresa de los presentes, les pasó una carpeta personal en el cual ya se les indicaba a cada uno de ellos los objetivos que debía lograr en su cartera y los plazos en que debían ser realizados durante los cuatro años de gobierno.Al mismo tiempo, Bachelet decidió establecer una serie de Comisiones de Estudios para que presentaran dentro de un plazo determinado una propuesta a la presidenta de la República.Así se constituyeron una Comisión sobre el sistema binominal a cargo de Edgardo Boeninger y una comisión sobre el sistema provisional, a cargo de Mario Marcel. Estas comisiones, que estaban constituidas mayoritariamente por expertos en la materia,${ }^{36}$ también incluían a representantes de la sociedad civil. A través de este último elemento, Bachelet trataba de darle forma a su promesa de convertirse en un 'gobierno ciudadano'. Sin embargo, a medida que ella comenzaba a acentuar en su discurso la 'participación ciudadana', comenzaba en Chile a gestarse una discusión a nivel académico de qué se podría entender específicamente por 'participación' de la ciudadanía en las políticas públicas y sus posibles impactos tanto en la efectividad de las políticas como en la estabilidad política en el país. ${ }^{37}$

La gran prueba de fuego sobre la participación ciudadana se produciría abruptamente a fines de mayo de 2006 cuando las organizaciones de estudiantes secundarios de Santiago hicieran un llamado a tomarse los establecimientos educacionales y a una huelga indefinida en pro de una mejora en la calidad de la educación. Esto generó una serie de violentos enfrentamientos callejeros entre escolares y fuerzas policiales. La acción de los estudiantes secundarios desencadenaría además la fuerte activación de variados movimientos sociales y de sectores radicales de la izquierda extraparlamentaria quienes solidarizarían con su lucha y también se tomaban las calles de la capital. Las imágenes de violencia callejera y de un alto grado de radicalización y de intransigencia por parte de los dirigentes estudiantiles, reavivaban el miedo de no pocos chilenos que el nuevo escenario terminara por acabar el clima de relativa tranquilidad y estabilidad política que el país había gozado desde la restauración democrática en 1990 e incluso que se pudiese recrear el clima de violencia política y social como el vivido a comienzos de los años 70 .

\footnotetext{
$36 \quad$ La comisión de reforma provisional sería justamente cuestionada por algunos sectores por su marcado carácter tecnocrático. En un artículo de El Mostrador se decía: "El equipo de la Presidenta Bachelet ha perdido una magnífica oportunidad de poner en práctica su proyecto de gobierno ciudadano cercano a las mayorías. Su composición es eminentemente tecnócrata, es decir, su mayoría son expertos y cuyas opiniones no serán vertidas como tales, sino que tendrán la pretensión de situarse en el campo de las pericias técnicas y de los saberes neutros (know how), no contaminados por los intereses económicos y políticos en juego”, 'Comisión de Reforma Provisional y la tecnocracia', El Mostrador, 10 de agosto de 2006.

$37 \quad$ Así, a partir de marzo de 2006 se han realizado una serie de encuentros y simposios sobre esta temática. Este es el caso de 'Participación ciudadana en la gestión pública en Chile', organizado conjuntamente por FLACSO-Chile y la Universidad de Leiden en Santiago a inicios de mayo de 2006.
} 
Los estudiantes exigían la conformación de una comisión, al igual a la existente sobre el sistema provisional, para estudiar los problemas de la educación y formular propuestas de cambios, en donde ellos tuvieran una representación mayoritaria. Los llamados al gobierno de sectores de derecha a mostrar autoridad y de sectores de la Concertación de mostrar habilidad política para desactivar la crisis, llevaron a Bachelet a imponer su voz en la conformación de la comisión, en la cual si bien hay una amplia representación de los estudiantes, quedó en manos de expertos. ${ }^{38}$

La crisis de los secundarios redujo además considerablemente los altos grados de autonomía con respecto a los partidos políticos que había logrado establecer Bachelet desde iniciada su candidatura presidencial hasta la crisis estudiantil. A saber, fueron los partidos políticos de la Concertación, y no el gobierno, que a través de sus estructuras internas y vía sus nexos partidarios con las organizaciones estudiantiles y los demás movimientos sociales involucrados, lograron finalmente tranquilizar los ánimos de los huelguistas y parar la crisis. Esto quedó simbolizado en la reunión que mantuvo Bachelet tras el fin de la crisis con todos los jefes de la Concertación, en que se veía la imagen de la hija pródiga que finalmente regresaba a su cuna original.

La crisis de los estudiantes secundarios, que de hecho representó una suerte de 'sobredosis' de participación ciudadana directa, dejó seriamente lesionado al recién establecido gobierno de Bachelet y sin duda debilitó al interior del gobierno a los partidarios del discurso 'ciudadano'. ${ }^{39}$ La crisis había dañado especialmente la posición del Ministro del Interior, Andrés Zaldívar y del Ministro de Educación, Martin Zilic, quienes serían acusados desde distintos sectores de no haber sabido conducir la crisis de una manera adecuada. Finalmente, Bachelet se vería obligada a hacer un ajuste de gabinete a sólo 4 meses de haber iniciado su gobierno, en donde saldrían los dos cuestionados ministros. Además, Bachelet vería caer rápidamente el grado de aprobación de su gobierno por parte de la población. ${ }^{40}$

La crisis de los secundarios, también produjo en ciertos círculos de opinión pública una abierta defensa de la democracia representativa y un cuestionamiento de los posibles beneficios que pudiera traer la democracia participativa. Bastante impacto tendría el artículo del influyente opinólogo Patricio Navia de julio de 2006 en donde $38 \quad$ Al presentar su propuesta de reformas educacionales, Bachelet dejaría en claro que era ella y no los estudiantes quien decidía finalmente sobre el asunto, afirmando a comienzo de su discurso que "este es un Gobierno que dialoga y después de escuchar y dialogar decide. He resuelto tomar nuevas medidas para garantizar que nuestros jóvenes estudian tranquilos y en buenas condiciones", La Segunda, 1 de junio de 2006.

39 Así, incluso Camilo Escalona, Presidente del Partido Socialista y leal colaborador de la presidenta, afirmaría que "Bachelet constituyó su gabinete y organizó su gobierno invitando a participar, pero esa participación ha sido mal asumida. Las demandas son tan numerosas y en algunos casos desproporcionadas que en lugar de diálogo tenemos desorden. , La Segunda, 12 de agosto de 2006.

$40 \quad$ En abril de 2006, un mes tras asumir la presidencia, Bachelet gozaba de un 62,1 por ciento de aprobación. En mayo el nivel de aprobación había bajado a un 54,2 por ciento y en junio de 2006 el índice de aprobación había caído al 44,2 por ciento; el más bajo índice que haya gozado un presidente de la Concertación desde 1990. Esta caída en la aprobación del gobierno, empero, no significó una mayor aprobación de los partidos de la oposición por parte de la población. Ello sería un reflejo de la pésima imagen que tienen los ciudadanos respecto a los partidos políticos en general. 
exigía a Bachelet aclarar que entendía ella exactamente por democracia participativa y en donde advertía sobre los peligros que traía consigo para la estabilidad política la democracia de las calles.

La tensión entre democracia representativa y democracia participativa está hoy en el centro de nuestro sistema político. (.) Bachelet ha expresado su preferencia por los gobiernos ciudadanos. Pero aunque la democracia participativa parece una vía razonable y atractiva (..) los que gritan más fuerte o tiran más piedras llevan las de ganar en la democracia participativa. (..) Nuestro país ya sufrió una vez con el irresponsable menosprecio de la democracia representativa. No podemos volver a cometer ese error. Sin duda que hay que mejorar la democracia representativa e introducir mecanismos que faciliten y fortalezcan el control ciudadano. Pero idealizar el pueblo en la calle y manifestar una nostálgica preferencia por el poder popular por sobre la democracia representativa constituye el peor error que puede cometer la izquierda en Chile hoy. ${ }^{41}$

Pareciera ser, en todo caso, que tras la crisis de los secundarios, se ha asentado el modus operandi de Bachelet para encarar los diversos temas y problemas nacionales, combinando el juicio de expertos en cada materia con la opinión de algunos sectores consultados de la sociedad civil. En otras palabras, se está dando cierta forma de articulación efectiva entre gestión tecnocrática y formas de consulta ciudadana. Esto podría estar llevando a una situación a la que Peter Evans (1995) ha llamado de 'embedded autonomy' en la cual la tecnocracia gubernamental abre canales reales de comunicación y consulta con representantes de los sectores sociales involucrados en cada tipo de decisiones, pero que al final del día son los cuadros técnicos y los responsables de las políticas públicas quienes, manteniendo su relativa autonomía de los grupos de presión en la sociedad, toman la decisiones finales. ${ }^{42}$

Por otro lado pareciera ser que aumento del protagonismo de los partidos políticos fue solo coyuntural tras la crisis de los secundarios. Si bien Bachelet después de la embestida estudiantil redujo visiblemente su grado de autonomía, aún ha sabido mantener altos grados de independencia, como se refleja en la manera como ha llevado junto a su ministro de relaciones exteriores, Alejandro Foxley, las relaciones internacionales, y en particular, las delicadas relaciones con los países vecinos. Aún no ha mandado grandes propuestas de reformas al parlamento, por lo cual no está claro que tan cooperativos serán los parlamentarios concertacionistas con la nueva Presi-

\footnotetext{
$41 \quad$ Patricio Navia, 'Poder popular', La Tercera, 1 de julio de 2006.

42 Las críticas por la constitución de estas comisiones de sello tecnocrático no se harían esperar. Carlos Huneeus, por ejemplo, ha argumentado que "la protesta estudiantil fue un golpe mayor no sólo al gobierno, sino también al sistema político. (..) Los jóvenes han devuelto la política al frente de la democracia, postergada por el tecnocratismo y el sesgo conservador de este. La protesta estudiantil tensiona a la Concertación pues se confrontan dos maneras de entender la acción del gobierno: una mirada 'técnica', con un recetario de policies, posible de ser compartida por 'expertos' de distintas ideologías, o una mirada política. (..) La mirada técnica desconoce los conflictos de intereses que hay en la sociedad, mientras que la mirada política los reconoce y los busca regular por consenso o por una norma de la mayoría", Qué Pasa, 10 de junio de 2006.
} 
denta. Pero no es impensable que, en ese momento, los partidos políticos decidan poner nuevamente a la Presidenta Bachelet bajo presión para aumentar así su grado de influencia ante su gobierno.

Lo que si ha quedado en claro tras el anuncio del gabinete ministerial de Bachelet en enero de 2006 es que el 'efecto Expansiva' ha producido una fuerte erosión en la función tradicional de los partidos políticos como principal ente de reclutamiento de la clase gobernante. ${ }^{43}$ Así, a partir de esa fecha se han establecido una serie de nuevos think tanks que tienen como objeto dar el respaldo técnico y político necesario a futuros 'presidenciables', creando ideas y formulando proyectos de futuras políticas públicas. ${ }^{44}$ En vista del carácter técnico-profesional que caracteriza a estos centros privados, obviamente este auge de los think tanks va en directo beneficio de individuos con expertise en terrenos y temas específicos y de perfil tecnocrático, en desmedro de los políticos tradicionales y de sus organizaciones políticas. ${ }^{45}$

\section{Comentarios finales}

La batalla entre tecnócratas y políticos al interior de la Concertación aún no ha sido definitivamente ganada por los primeros. En los próximos años, seguramente el gobierno de Bachelet deberá enfrentar una constante presión de parte de los sectores más de izquierda de la Concertación para que baje su perfil tecnocrático y fortalezca los mecanismos en pro de la participación ciudadana. Al mismo tiempo, su gobierno se verá constantemente asediado por la clase dirigente del Partido Demócrata Cristiano y del eje PS-PPD, quienes continuarán presionando para intentar recuperar las cuotas de poder que han tenido que ceder a los sectores tecnocráticos. La abierta envestida lanzada por el senador democratacristiano Adolfo Zaldívar a fines de 2007

\footnotetext{
43 Hay analistas que ven en Expansiva una suerte de proto-partido o de partido político sui generis, ya que sin tener estructuras partidistas ni representación parlamentaria, ha sido capaz de apoderarse de una buena cuota de poder dentro del gobierno de Bachelet. Otros advierten que Expansiva podría convertirse en el tiempo en una suerte de partido bacheletista.

${ }_{44} \quad$ Este es el caso de la Fundación 'ProyectAmerica', a cargo del ex senador José Antonio Viera-Gallo y que reúne a diversas figuras de la Concertación que no fueron incluidas en el gobierno de Bachelet. El ex presidente Lagos ha creado 'Democracia y Desarrollo' que oficialmente tiene como objetivo de cuidar el legado de su obra y su proyección internacional, pero que es visto como una posible plataforma electoral para las elecciones presidenciales de 2009. Por su parte Joaquín Lavín creó el centro de investigación 'Vanguardia', mientras el dirigente de la UDI, Pablo Longueira, quien ha hecho manifiesto su interés de convertirse en el abanderado de la derecha para el 2009, ha creado la Fundación 'Chile Justo'. Por otro parte, el centro CIEPLAN, que prácticamente quedó paralizado desde 1990 cuando Foxley y los suyos pasaron a formar parte del gobierno de Aylwin, ha sido renovada y apuntalada con la designación de Ignacio Walter, ex ministro de relaciones de Lagos y prestigioso politólogo, como su nuevo director.Véase, ‘¿Para qué sirven los think tanks?', La Tercera, 2 de abril de 2006; 'El efecto Expansiva en la derecha', La Nación, 23 de abril de 2006; '¿Todo el poder a los think tank?, La Nación, 27 de abril de 2006.

45 Ya habíamos advertido al comienzo del gobierno de Aylwin sobre el gran futuro que tendrían los think tanks en la realidad política chilena. En aquel entonces afirmamos que "the key role played by the technocrats of CIEPLAN in the new government also shows the increasing importance that research institutes have attained within Chilean politics, to the detriment of political parties, as reservoirs of an alternative techno-political class. The Chicago boys have also received the message, establishing a CIEPLAN-like think tank in order to monitor the performance of the Aylwin government and to wait for political change in the future for the deployment of their policies. The struggle for political power between competing technocratic groups entrenched in their respective think tanks has become a new feature of Chilean politics" (Silva, 1991: 409-410).
} 
en contra de la 'trasversalidad' que se ha logrado en el seno del estamento tecnocrático al interior del gobierno - que va en detrimento del poder y la influencia de los dirigentes políticos tradicionales - es un vivo ejemplo de esta lucha entre políticos y tecnócratas.

El evidente fracaso del nuevo sistema de trasportes (Transantiago) ha sido un duro golpe para la tecnocracia gubernamental. Tanto la oposición de derecha, como las voces disidentes de izquierda al interior de la Concertación (los llamados 'díscolos'), como los medios de comunicación y la ciudadanía en general han culpado abiertamente a los tecnócratas de gobierno como los principales responsables de este debacle. Sin embargo, la presidenta Bachelet aún no da señales de estar dispuesta a alejarse de sus principales colaboradores de seño tecnocrático. De hecho, nombró a René Cortázar, ex ministro y destacado ex-economista de CIEPLAN que posee claras credenciales tecnocráticas, como encargado de solucionar los problemas producidos por la aplicación del Transantiago. En mi opinión, el estamento tecnocrático se ha convertido en un componente estructural del 'bacheletismo' y la posibilidad de que el presente gobierno los reemplace por los partidos políticos como su principal base de apoyo en el proceso de toma de decisiones se hace muy improbable en los años que le restan de gobierno. 
Revista de Sociología 21 / 2007 Chile Hoy

Facultad de Ciencias Sociales - Universidad de Chile

\section{Bibliografía}

Angell, Alan. 2005. Elecciones presidenciales, partidos políticos y democracia en el Chile post Pinochet. Santiago: Ediciones Centro de Estudios Bicentenario.

Angell, Alan. 2007. Democracy after Pinochet: Politics, Parties and Elections in Chile. London: Institute for the Study of the Americas.

Boeninger, Eduardo. 1997. Democracia en Chile: Lecciones para la gobernabilidad. Santiago: Editorial Andrés Bello.

Centeno, Miguel A. and Sylvia Maxfield. 1992."The Marriage of Finance and Order: Changes in the Mexican Political Elite." Journal of Latin American Studies 24, no. 1: $57-85$

Cleaves, Peter. 1974. Bureaucratic Politics and Administration in Chile. Berkeley, CA: University of California Press.

Cortázar, René. 1993. Política laboral en el Chile democrático: Avances y desafíos en los noventa. Santiago: Dolmen.

Délano, Manuel and Hugo Translaviña. 1989. La herencia de los Chicago Boys. Santiago: Ediciones del Ornitorrinco.

Domínguez, Jorge I. (ed.). 1996. Technopols: Freeing Politics and Markets in Latin America in the 1990s. University Park, PA: Penn State University Press.

Drake, Paul W. and Iván Jaksic (eds.). 1991. The Struggle for Democracy in Chile, 1982-1990. Lincoln and London: University of Nebraska Press.

Fischer, Frank. 1990. Technocracy and the Politics of Expertise. Newbury Park, CA: Sage.

Fontaine, Arturo. 1989. La historia no contada de los economistas del presidente Pinochet. Santiago: Editorial Zig-Zag.

Foxley, Alejandro. 1983. Latin American Experiments in Neoconservative Economics. Berkeley, CA: University of California Press.

Garretón, Manuel Antonio. 1989. The Chilean Political Process. Boston, MA: Unwin Hyman.

Giraldo, Jeanne K. 1996. "Development and Democracy in Chile: Finance Minister Alejandro Foxley and the Concertación Project for the 1990s." In Technopols: Freeing Politics and Markets in Latin America in the 1990s, edited by Jorge I. Domínguez, 229-75. University Park, PA: Penn State University Press. 
Estilos Políticos y Orientación Tecnocrática bajo los Gobiernos de Lagos y Bachelet / Patricio Silva

Halpern, Pablo. 2002. Los Nuevos Chilenos y la batalla por sus preferencias. Santiago: Planeta.

Huneeus, Carlos. 2007. The Pinochet Regime. Boulder, CO: Lynne Rienner. [2001].

Lavín, Joaquín. 1987. Chile: Revolución silenciosa. Santiago: Zig-Zag.

Lavín, Joaquín and Luis Larraín. 1989. Chile: Sociedad emergente. Santiago: Zig-Zag.

Montecinos, Verónica. 1998. Economists, Politics and the State: Chile 1958-1994. Amsterdam: CEDLA.

Moulian, Tomás. 1997. Chile actual: Anatomía de un mito. Santiago: LOM.

Navia, Patricio. 2004. Las grandes alamedas: El Chile post Pinochet. Santiago. La TerceraMondatori.

O’Donnell, Guillermo. 1973. Modernization and Bureaucratic-Authoritarianism: Studies in South American Politics. Berkeley: Institute of International Studies, University of California.

O’Donnell, Guillermo, Phillipe Schmitter, and Laurence Whitehead (eds.). 1986. Transitions from Authoritarian Rule. Baltimore, MD: The Johns Hopkins University Press.

Puryear, Jeffrey M. 1994. Thinking Politics: Intellectuals and Democracy in Chile, 19731988. Baltimore, MD: Johns Hopkins University Press.

Putnam, Robert D. 1977. "Elite Transformation in Advanced Industrial Societies:An Empirical Assessment of the Theory of Technocracy." Comparative Political Studies 10, no. 3: 383-412.

Rabkin, Rhoda. 1993. "How Ideas become Influential: Ideological Foundations of Export-led Growth in Chile, (1973-90)" World Affairs 156, no. 1:3-25.

Ree, Gerard van der. 2007. Contesting Modernities: Projects of Modernisation in Chile, 1964-2006. Amsterdam: Dutch University Press.

Scully, Timothy R. 1992. Rethinking the Center: Party Politics in Ninetieth-and Twentieth-Century Chile. Stanford, CA: Stanford University Press.

Silva, Eduardo. 1996. The State and Capital in Chile: Business Elites, Technocrats, and Market Economics. Boulder, CO:Westview Press.

Silva, Patricio. 1983. "Intellectuals, Technocrats and Social Change in Chile: Past, Pre- 
ReVista de Sociolocía $21 / 2007$ CHILE Hoy

Facultad de Ciencias Sociales - Universidad de Chile

sent and Future Perspectives." In The Legacy of Dictatorship: Political, Economic and Social Change in Pinochet's Chile, edited by Alan Angell and Benny Pollack, 198-216. Liverpool: University of Liverpool, Institute of Latin American Studies.

Silva, Patricio. 1987. Estado, neoliberalismo y política agraria en Chile, 1973-1981. Amsterdam: CEDLA.

Silva, Patricio. 1991. "Technocrats and Politics in Chile: from the Chicago Boys to the CIEPLAN Monks." Journal of Latin American Studies 23, no. 2: 385-410.

Silva, Patricio. 1992. "Intelectuales, tecnócratas y cambio social en Chile: Pasado, presente y perspectivas futuras.” Revista Mexicana de Sociología 54, no. 1: 139-66.

Silva, Patricio. 1993a. "Intellectuals, Technocrats and Social Change in Chile: Past, Present and Future Perspectives." In The Legacy of Dictatorship: Political, Economic and Social Change in Pinochet's Chile, edited by Alan Angell and Benny Pollack, 198-223. Liverpool: Institute of Latin American Studies Monograph Series.

Silva, Patricio. 1993b. "State, Politics and the Idea of Social Justice in Chile." Development and Change 24: 465-86.

Silva, Patricio. 1994. "State, Public Technocracy and Politics in Chile, 1927-1941." Bulletin of Latin American Research 13 no. 3: 281-97.

Silva, Patricio. 1995. "Intellectuals and Technocrats in the Third World: Towards a Convergency?" In Designers of Development: Intellectuals and Technocrats in the Third World, edited by Benno Galjart and Patricio Silva, 269-78. Leiden: Centre for Non-Western Studies.

Silva, Patricio. 1997. "Going Asia: Economic Internationalization and Technocratic Empowerment in Chilean Foreign Policy." Paper presented at the XX LASA Congress, Guadalajara, México, April 17-19.

Silva, Patricio. 1998. "Pablo Ramírez, A Technocrat Avant-La-Lettre." In The Politics of Expertise in Latin America, edited by Miguel A. Centeno and Patricio Silva, 52-76. Basingstoke: Macmillan.

Silva, Patricio. 2000. "Politics Across Frontiers: The Pinochet Affair and Chilean Democracy." In Fronteras: Towards a Borderless Latin America, edited by Pitou van Dijck et al., 151-63. Amsterdam: CEDLA .

Silva, Patricio. 2001a. "Forging Military-Technocratic Alliances: The Ibáñez and Pinochet Regimes in Chile." In The Soldier and the State in South America: Essays in Civil-Military Relations, edited by Patricio Silva, 87-108. London and New York: Palgrave. 
Estilos Políticos y Orientación Tecnocrática bajo los Gobiernos de Lagos y Bachelet / Patricio Silva

Silva, Patricio. 2001b. "Towards Mass Technocratic Politics in Chile? The 19992000 Elections and the "Lavín Phenomenon." European Review of Latin American and Caribbean Studies 70: 25-39.

Silva, Patricio. 2003. "Democratisation and State-Civil Society Relations in Chile, 1983-2000: From Effervescence to Deactivation," Nordic Journal of Latin American and Caribbean Studies 32, no. 2: 73-96.

Silva, Patricio. 2004. "Doing Politics in a Depoliticised Society: Social Change and Political Deactivation in Chile." Bulletin of Latin American Research 23, no. 1: 63-78.

Silva, Patricio. 2006a. "Lastarria, Letelier and 'Scientific Politics' in Chile." Revista Bicentenario 5, no. 2: 85-114.

Silva, Patricio. 2006b. "Los tecnócratas y la política en Chile: Pasado y Presente.”Revista de Ciencia Política 26, no. 2:171-186.

Silva, Patricio. 2008. In the Name of Reason:Technocrats and Politics in Chile. University Park, PA: Penn State University Press.

Tironi, Eugenio. 2005. El sueño chileno: Comunidad, familia y nación en el Bicentenario. Santiago: Aguilar.

Toha, Carolina and Ricardo Solari. 1996. "La modernización del Estado y la gerencia pública." Santiago: Friedrich Ebert Stiftung.

UNDP [United Nation Development Program]. 1998. Las paradojas de la modernización. Santiago: UNDP.

UNDP [United Nation Development Program]. 2002. Desarrollo Humano en Chile: Nosotros los chilenos, un desafío cultural. Santiago: UNDP.

UNDP [United Nation Development Program]. 2004. El poder: ¿Para qué y para quién? Santiago: UNDP.

Vergara, Pilar. 1985. Ange y caída del neoliberalismo en Chile. Santiago: FLACSO. 